\title{
Re: "Seroprevalence of Borrelia IgM and IgG Antibodies in Healthy Individuals: A Caution Against Serology Misinterpretations and Unnecessary Antibiotic Treatments" by Strizova et al.
}

\author{
Miriam F. Weiss
}

$\mathbf{S}$ TRIZOVA ET AL.'s (2020) recent review article focuses on $\checkmark$ the inaccuracy of serologic diagnosis in Lyme disease. We agree that serologic testing alone is not sufficient for diagnosis. However, we wish to call your readers' attention to research that suggests persistent positivity for IgM antibodies is an important sign of chronic infection by the Lyme spirochete.

Borrelia burgdorferi has been shown to manipulate both the innate and adaptive immunity of its mammalian hosts in a variety of ways (Tracy and Baumgarth 2017). Early in infection, it migrates to the lymph nodes (Tunev et al. 2011). There it interferes with the maturation of memory B cells, and causes the failure to develop long-term immunity (Elsner et al. 2015).

In short, the persistence of $\operatorname{IgM}$ antibodies in Lyme disease may represent chronicity, not a false positive. The classical pattern of B cell maturation and the IgM to IgG transition are lacking in chronic infection by Borrelia burgdorferi. The organism abrogates the development of highly specific longterm immunity to persist in the host (Elsner et al. 2015).

\section{References}

Elsner RA, Hastey CJ, Baumgarth N. CD4+ T cells promote antibody production but not sustained affinity maturation during Borrelia burgdorferi infection. Infect Immun 2015; 83:48-56.

Elsner RA, Hastey CJ, Olsen KJ, Baumgarth N. Suppression of long-lived humoral immunity following Borrelia burgdorferi infection." PLoS Pathog 2015; 11:e1004976.

Strizova Z, Smrz D, Bartunkova J. Seroprevalence of Borrelia IgM and IgG antibodies in healthy individuals: A caution against serology misinterpretations and unnecessary antibiotic treatments. Vector Borne Zoonotic Dis 2020; 10:800-802.

Tracy KE, Baumgarth N. Borrelia burgdorferi manipulates innate and adaptive immunity to establish persistence in rodent reservoir hosts. Front Immunol 2017; 8:116.

Tunev SS, Hastey CJ, Hodzic E, Feng S, et al. Lymphoadenopathy during lyme borreliosis is caused by spirochete migration-induced specific B cell activation. PLoS Pathog 2011; 7:e1002066.
Address correspondence to

Miriam F. Weiss, MD, MA

3600 Park East Drive, Apartment 519

Beachwood, Ohio 44122

$U S A$

E-mail:maf3@case.edu

Department of Bioethics, Case Western Reserve University School of Medicine, Cleveland, Ohio, USA.

(C) Miriam F. Weiss, 2020; Published by Mary Ann Liebert, Inc. This Open Access article is distributed under the terms of the Creative Commons License (http://creativecommons.org/licenses/by/4.0), which permits unrestricted use, distribution, and reproduction in any medium, provided the original work is properly cited. 